\title{
Does the blindness affect the behavioural activities of rabbit?
}

\author{
Karim El-Sabrout
}

K El-Sabrout (Corresponding author)

Department of Poultry Production, Faculty of Agriculture (El-

email: kareem.badr@alexu.edu.eg

Shatby), University of Alexandria, Alexandria, Egypt.

Received: September 18, 2017 • Revised: October 12, 2017 • Accepted: October 13, 2017

\begin{abstract}
Blindness is a condition characterized by the limited or complete loss of a rabbit's eyesight. Rare is known about its effect on behavioural activities of rabbit. The aim of this study was to investigate the effect of genetically blindness on some behavioural activities of V-line rabbits and its reflexion on productive performance. Behavioural comparison between the normal and the blind rabbits was carried out to study this effect. The results demonstrate that it was no significant effect of blindness on feeding, drinking, waking, nervousness, sexual desire and maternal care of rabbits. Accordingly, there are no significant differences on body weight (weaning marketing), litter size and milk yield between the normal and the blind rabbits. Blindness is a recessive character. Rabbits depend primarily on smell and hearing senses. The blind rabbits can adapt its live well and have a wonderful life.
\end{abstract}

Keywords: feed behaviour, maternal care, sexual behaviour

\section{Introduction}

The eyes of the rabbit are designed to give them the ability to be able to see through almost 360 degrees (Williams 2007). Vision behaviour involves moving the head up/down when viewing something in the distance and rabbits try to stand up on their hind legs to get a better look around them (Tynes 2010). They have poor vision up close and the night vision of the rabbit is almost certainly extremely poor (Jilge 1991). Also, rabbits are protanopic animals; it is a form of colour blindness characterized by a tendency to confuse reds and greens and by a loss of sensitivity to red light (Kelber et al 2003).

Sometimes rabbits are born blind due to genetically mutation, congenital issues, trauma and other reasons related with the surrounding environmental conditions. Regardless of the causes of blindness, rabbits try to adapt without their sight. They will be able to smell their food and their kits inside the cages but may have trouble navigating outside (Williams 2007).

There are general behavioural signs of blind rabbit include delayed response to visual stimuli, cautious movements, clinging to cage or objects when exploring and nervousness in new places. Physical signs of eye blindness include receding eyeball, enlargement of the eye, redness around the eye and cloudy appearance to the eye (Figure 1) (Williams 2007).

Few researches have been published to improve the effect of blindness on rabbit behaviour. Therefore, the present study was carried out to investigate the effect of genetically blindness on the behavioural activities of $\mathrm{V}$-line rabbits and its reflexion on productive performance.

\section{Materials and Methods}

Animal, housing, feeding and mating management

This experiment was conducted on normal and blind rabbit's does from V-line stocks. Rabbits were housed in cages and were offered ad libitum access to drink and fed commercial pelleted diet containing $18 \%$ crude protein, $13 \%$ crude fiber and $2600 \mathrm{Kcal} / \mathrm{Kg}$. The breeding rabbits were divided into families; each family was made by four does and one buck (sex ratio) that was chosen to avoid breeding of close relatives relationships. At the mating time, each doe was transferred to the buck's cage, and they left with bucks about 10-15 min after success of the first copulation and then returned to their cage. By using high standard hygiene and good management, the happening of dangerous diseases was largely avoided all through the experimental period. The study was approved by Alexandria University Animal Ethics.

Behavioural activities

All rabbits have been monitored from day-one till the end of the experiment. The following behavioural activities were recorded: feeding, drinking, walking, nervousness, sexual desire and maternal care. The state behavioural activities were represented as percentage using a scale from 1 (poor quality) to 5 (high quality) according to Farghly et al (2015). 


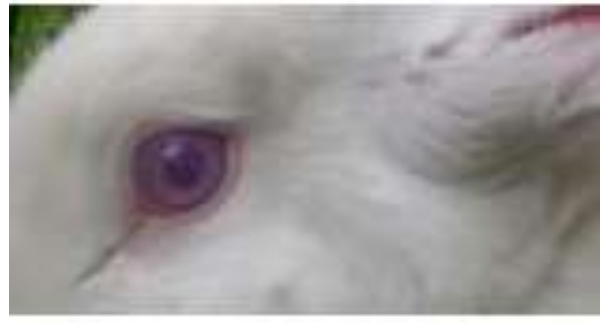

Figure 1 Blind V-line rabbit.

Productive performance

Data were collected on individual body weight $(\mathrm{g})$ at 28 days (weaning) (BW1), individual body weight (g) at 63 days of age (marketing age) (BW2), litter size (LS) at birth and milk yield (MY) (ml/day) during the 3rd week of lactation.

Statistical analysis

The behavioural activities were shifted and rescaled to give approximate normality and equal variance, with parameters converted by arcsine transformation. The transformed data were analyzed by the general linear model (GLM) procedure of SPSS (2011). Statistics of means differences in productive performance traits were determined by ANOVA followed by Duncan's multiple range test using SPSS (2011).

\section{Results}

From the results of Table (1), there were no significant differences between the normal and the blind rabbit's does in the behavioural activities (feeding, drinking, waking, nervousness, sexual desire and maternal care). Consequently, there were no significant differences in productive performance (body weight at weaning, body weight at marketing, litter size and milk yield) between the normal and the blind rabbit's does. It means that the blindness have no significant effect on rabbit behaviour or its productive performance. In addition, all the blind does use in this study have normal kits. It means that the blindness is a recessive trait. The blind rabbits can adapt its live well depending on its good smell and hearing senses.

Table 1 Effect of blindness on behavioural activities and productive performance of V-line rabbits.

\begin{tabular}{lccc}
\hline \hline & Normal rabbits & Blind rabbits & Significance \\
\hline Behavioural activities & $(\mathrm{n}=15)$ & $(\mathrm{n}=5)$ & $\mathrm{ns}$ \\
Feeding (\%) & 97 & 95 & $\mathrm{~ns}$ \\
Drinking (\%) & 98 & 96 & $\mathrm{~ns}$ \\
Walking (\%) & 91 & 88 & $\mathrm{~ns}$ \\
Nervousness (\%) & 65 & 68 & $\mathrm{~ns}$ \\
Sexual desire (\%) & 92 & 90 & $\mathrm{~ns}$ \\
Maternal care (\%) & 97 & 98 & $\mathrm{~ns}$ \\
Productive performance & $(\mathrm{n}=155)$ & $(\mathrm{n}=53)$ & $\mathrm{ns}$ \\
BW1 (g) & $665.11 \pm 10.55$ & $668.02 \pm 10.50$ & $\mathrm{~ns}$ \\
BW2 (g) & $1458.19 \pm 16.00$ & $1462.01 \pm 18.03$ & $\mathrm{~ns}$ \\
LS (n) & $9.2 \pm 0.18$ & $9.1 \pm 0.11$ & $(\mathrm{n}=5)$ \\
MY (ml/day) & $(\mathrm{n}=15)$ & $244 \pm 0.01$ & \\
\hline \hline
\end{tabular}

$\mathrm{Ns}=$ not significant at $(\mathrm{P}<0.05) . \mathrm{V}=\mathrm{V}$-line; BW1= individual body weight at weaning age;

$\mathrm{BW} 2=$ individual body weight at marketing age; $\mathrm{LS}=$ litter size; $\mathrm{MY}=$ milk yield.

\section{Discussion}

Behaviour understanding of animal is very important; it can impact its live activities, and its productive traits. Unfortunately, few studies were interest in rabbit behaviour. The current study was interest in blind rabbit behaviour, especially the blindness due to the genetic mutation or some hereditary factors that affect their eyesight. Blind rabbits represent small percentage from whole stock, although there are many reasons for this blindness. Some procedures prefer to eliminate or remove them from the stock and never included them in their breeding stock. But from the results of this study, i can emphasize that it is not necessary and we can use these rabbits in breeding and production.

The results of this study showed that the blindness have no significant effect on rabbit behaviour or its productive performance. Whereas the rabbit can compensated its blindness by its good hearing and smell. Rabbits live in underground tunnels, which helps to keep them save and hidden from other predatory animals. Rabbits can adapt 
remarkably well to life with limited or no sight (Tynes 2010). Blind rabbits tend to move carefully inside the cage as a way of investigating their surroundings. It can be difficult to adjust at first, but finally the blind rabbits can find their way around, explore and continue its live.

The productive performance of rabbit depends heavily on its behaviour activities (Marai and Rashwan 2003). The studied sexual desire behaviour was in agreement with ElSabrout (2017). The studied feeding behaviour and the productive traits were also in agreement with (El-Sabrout and Aggag 2017). Since it was no significant behaviour difference detected between the normal and blind rabbits, it was also no significant difference for its productive performance.

\section{Conclusions}

According to the results of this study, it was no significant effect of blindness on behavioural activities and productive performance of rabbit. Rabbits rely primarily on its good smell and hearing senses. The blind rabbits can adapt its live well and have a wonderful life. Further researches through expanded sampling and detailed studies will be required to provide more explanations.

\section{Conflict of interest}

The author declares that there is no known conflict of interest associated with this publication.

\section{Acknowledgements}

Special thanks to the director of Poultry Research Center, Alexandria University, and his great team for their technical support during the experiment.

\section{References}

El-Sabrout K (2017) Associations between single-nucleotide polymorphisms of melanocortin gene and sexual desire behaviour in rabbit (Oryctolagus cuniculus). Journal of Veterinary Behavior 19: 69-71.

El-Sabrout K, Aggag SA (2017) Associations between single nucleotide polymer-phisms in multiple candidate genes and body weight in rabbits. Veterinary World 10: 136-139.

Farghly MF, Mahrose KhM, Abou-Kassem DE (2015) Pre and post hatch performance of different Japanese quail egg colors incubated under photostimulation. Asian Journal of Poultry Science 9: 19-30.

Jilge B (1991) The rabbit: a diurnal or a nocturnal animal. Journal of Experimental Animal Science 34: 170-183.

Kelber, A, Osorio, D, Vorobyev, M (2003) Animal colour visionbehavioural tests and physiological concepts. Biological reviews of the Cambridge Philosophical Society 78: 81-118.
Marai FM, Rashwan AA (2003) Rabbit behaviour under modern commercial production conditions. Archives Tierzucht Dummerstorf 46: 357-376.

SPSS, Statistical Package for the Social Sciences (2011) SPSS User's Guide: Statistics, Version 20.0 for Windows, Institute, Inc., Cary, NC, USA.

Tynes V (2010) Behaviour of Exotic Pets. Wiley Blackwell, p. 70.

Williams D (2007) Rabbit and rodent ophthalmology. European Journal of Companion Animal Practice 17: 242-250. 